\title{
Aminoacylation and conformational properties of yeast mitochondrial tRNA mutants with respiratory deficiency
}

\author{
SILVIA FRANCISCI, ${ }^{1}$ CRISTINA DE LUCA, ${ }^{1}$ ROMINA OLIVA, ${ }^{2}$ VERONICA MOREA, ${ }^{3}$ ANNA TRAMONTANO, ${ }^{2}$ \\ and LAURA FRONTALI \\ ${ }^{1}$ Department of Cell and Developmental Biology, Pasteur Institute-Cenci Bolognetti Foundation; ${ }^{2}$ Department of Biochemical Sciences \\ "A. Rossi Fanelli"; and ${ }^{3}$ CNR-Institute of Molecular Biology and Pathology (IBPM), University of Rome "La Sapienza," 00185 Rome, Italy
}

\begin{abstract}
We report the identification and characterization of eight yeast mitochondrial tRNA mutants, located in mitochondrial tRNA $^{\mathrm{Gln}}$, tRNA $^{\mathrm{Arg}^{2}}$, tRNA $^{\mathrm{lle}}$, tRNA $^{\mathrm{His}}$, and tRNA ${ }^{\mathrm{Cys}}$, the respiratory phenotypes of which exhibit various degrees of deficiency. The mutations consist in single-base substitutions, insertions, or deletions, and are distributed all over the tRNA sequence and structure. To identify the features responsible for the defective phenotypes, we analyzed the effect of the different mutations on the electrophoretic mobility and efficiency of acylation of the mutated tRNAs in comparison with the respective wild-type molecules. Five of the studied mutations determine both conformational changes and defective acylation, while two have neither or limited effect. However, variations in structure and acylation are not necessarily correlated; the remaining mutation affects the tRNA conformation, but not its acylation properties. Analysis of tRNA structures and of mitochondrial and cytoplasmic yeast tRNA sequences allowed us to propose explanations for the observed defects, which can be ascribed to either the loss of identity nucleotides or, more often, of specific secondary and/or tertiary interactions that are largely conserved in native mitochondrial and cytoplasmic tRNAs.
\end{abstract}

Keywords: yeast; mitochondria; tRNA sequence; structure analysis

\section{INTRODUCTION}

The biogenesis of mitochondria requires the coordinated expression of genes located both on nuclear and mitochondrial (mt) DNA. The mt genome encodes components of the mitochondrial protein synthesis machinery including, in yeast, 24 tRNAs, the large and small mt rRNAs, the ribosomal protein var1, and the 9S RNA necessary to mature the $5^{\prime}$-end of the tRNA precursors. Mutations in one of these genes can result in defective mitochondrial protein synthesis and, consequently, in respiratory deficiency.

A number of point mutations in yeast tRNA genes have been described (Berlani et al. 1980; Najarian et al. 1986; Zennaro et al. 1989; Francisci et al. 1998; Rohou et al. 2001; Feuermann et al. 2003). The mutations may lead to faulty maturation of precursor tRNAs (due to the lack of recognition of the tRNA precursor by the maturation enzymes) or result in the production of mature but nonfunctional

Reprint requests to: Silvia Francisci, Department of Cell and Developmental Biology, University of Rome "La Sapienza," Piazzale Aldo Moro 5, 00185 Rome, Italy; e-mail: Silvia.Francisci@uniromal.it; fax: 39-064461980 .

Article and publication are at http://www.rnajournal.org/cgi/doi/ $10.1261 /$ rna.2260305.
tRNA; therefore, the study of these mutants might reveal features of mitochondrial tRNAs necessary for their function and/or recognition by cognate proteins. These mutants can also be useful to identify the nuclear genes, the products of which interact with the mitochondrial tRNAs.

We describe here the detailed characterization of eight tRNA mutants originally isolated by Berlani et al. (1980). The mutations were located in five different tRNA genes, and in all cases, sequencing analysis revealed a single base change (one insertion, one deletion, and six base substitutions). We studied the presence and acylation properties of all of these mutated tRNAs by Northern blot experiments and compared them with the respective wild-type molecules. Mapping of our experimental data on tRNA sequences and structures enabled us to draw conclusions about the relationships between the modifications introduced by the mutations in the tRNAs and the defective yeast phenotype.

\section{RESULTS}

\section{Identification of the mutations}

The mutants used in this work had been selected by Berlani et al. (1980) on the basis of slow, thermosensitive, 
or defective cell growth on glycerol-containing media. We have performed a more extensive characterization of their growth in glycerol at $28^{\circ} \mathrm{C}$ and $37^{\circ} \mathrm{C}$, which is reported in Figure 1. For each mutated strain, the region of the $\mathrm{mt}$ DNA where the mutation had been roughly located was amplified by PCR and sequenced. The location of each mutation and the growth phenotype are reported in Table 1. In Figure 2, we show the deduced cloverleaf structure for the wild-type tRNA ${ }^{\text {Gln }}$, where the changes occurring in each mutant are highlighted. The tRNA "L"-shaped molecule is composed by the acceptor (AA), dihydrouracil (D), anticodon (AC), and T $\Psi \mathrm{C}(\mathrm{T})$ stems, and by the dihydrouracil, anticodon, variable $(\mathrm{V})$, and TYC loops. The AA and $\mathrm{T}$ stems form one continuous double-helical arm, while the $\mathrm{D}$ and anticodon stems form the other long doublehelical arm of the "L". Tertiary interactions are mediated by nonstandard base interactions at the junction of the two helices, where the loop regions of the $\mathrm{T}$ and $\mathrm{D}$ arms form an elbow.

In the same figure, we also show the partial cloverleaf structures of the tRNA regions where other mutations were located. Sequencing revealed one insertion at position 5 , one substitution at position 6 , and one substitution at position 10 in tRNA ${ }^{\text {Gln }}$ (mutants ins5U, C6U, and G10U, respectively); one G51A substitution in the tRNA ${ }^{\text {His }} \mathrm{T} \Psi \mathrm{C}$ stem, one G36A transition in the AC loop for mutant G36A and one $\mathrm{U} 45$ deletion in the $\mathrm{V}$ loop for mutant $\mathrm{U} 45 \Delta$ of the tRNA $^{\text {Arg2 }}$, one U41C substitution in the tRNA ${ }^{\text {Ile }}$ anticodon stem and one $\mathrm{C} 66 \mathrm{U}$ transition in the AA stem of tRNA ${ }^{\text {Cys }}$.

\section{Transcription and acylation of the mutated tRNAs}

For each mutant, we checked the presence of the mature specific tRNA by Northern blot experiments followed by hybridization to a $5^{\prime}$-end-labeled oligonucleotide complementary to the studied mt tRNA.

Routinely, transcripts were separated in both completely and partially denaturing gels. In completely denaturing, agarose (data not shown) or polyacrylamide gels (see example in Fig. 3B), the mutated tRNAs were in all cases present in similar amounts to the wild-type and comigrated with the wild-type molecules, indicating that they have the same size and that no processing defects are present. In partially denaturing polyacrylamide gel (shown in Figs. 3, 4, 5), some of the mutated tRNAs had a lower mobility compared with the wild-type molecules, which we ascribe to a structural change. Additionally, we tested the acylation state of all mutated tRNAs by comparing their migration pattern to that of the wild-type molecules in acidic-gel. The presence of acylated tRNAs was inferred by a change in mobility following the deacylation treatment (see Materials and Methods).

Hybridization experiments were repeated at least three times, and in all cases, the same RNA sample (crude extract or treated for deacylation) was hybridized with a different mt-tRNA probe to ascribe the molecular defect to the specific tRNA mutation and not to a general effect, for example, on the protein synthesis process (lower panels of Figs. 3A, 4B, 5C bottom). To investigate a possible temperature effect on the mutated tRNAs, all hybridization experiments were performed with samples extracted from cells grown at $28^{\circ} \mathrm{C}$ and $37^{\circ} \mathrm{C}$.

\section{Mutants C6U, G10U, and ins5U of tRNA $A^{G / n}$}

Figure $3 \mathrm{~A}$, upper panel, shows the mobility of the wild-type tRNA $^{\text {Gln }}$ and of the three mutated tRNA ${ }^{\text {Gln }}$ (C6U, G10U, and ins5U) in partially denaturing acrylamide gel. In Figure $3 \mathrm{~A}$, bottom panel, the correspondent control with a mt Gly probe is shown. The three mutated tRNAs ${ }^{\text {Gln }}$ migrate more slowly than the wild-type, indicating that a structural change has occurred. In fact, in totally denaturing gel (Fig. 3B), the $\mathrm{C} 6 \mathrm{U}$ mutated molecule comigrates with the wild-type tRNA ${ }^{\text {Gln }}$.

The effect of the mutations on tRNA aminoacylation is shown in Figure 3C. In the wild type, the deacylated form of tRNA ${ }^{\mathrm{Gln}}$, migrating faster, can be distinguished from the aminoacylated one. The deacylation treatment had no effect on the C6U- and G10U-mutated tRNAs; therefore, we can hypothesize that the mutations C6U and G10U in tRNA $^{\text {Gln }}$ abolish acylation. The effect of the insertion at position 5 (ins5U) on tRNA aminoacylation is less evident. However, a lower proportion of acylated molecules was present compared with the wild type, and they were completely deacylated by the alkaline treatment. The different migration of the deacylated wild-type and mutated tRNAs suggests that the conformation of the mutant differs from that of the wild-type molecule (Fig. 3C).

\section{Mutant G51A of tRNA His}

Figure 4 shows the Northern blot experiment of total $\mathrm{mt}$ RNAs extracted from wild-type and mutant G51A cells and separated in acrylamide gels. Hybridization with the "His probe" (Fig. 4A,C) shows two strong signals present in both wild-type and mutant extracts. Bands from mutant cells, grown at $28^{\circ} \mathrm{C}$ and $37^{\circ} \mathrm{C}$, migrate more slowly than the wild-type samples (Fig. 4A), while the mobility is the same in the control experiment (hybridization with "Cys probe") (Fig. 4B). In order to obtain information on the peculiar double band shown by tRNA ${ }^{\text {His }}$, we tested it for acylation (Fig. 4C). The gel shows the two bands corresponding to the acylated and deacylated tRNA ${ }^{\mathrm{His}}$. In wildtype cells, a large amount of $\mathrm{mt} t \mathrm{RNA} \mathrm{H}^{\mathrm{His}}$ is present in the uncharged faster migrating form, and the deacylation treatment strongly increases this signal, allowing it to be identified as the mature uncharged tRNA ${ }^{\text {His }}$. A similar pattern is observed for the G51A mutant. As we are measuring the level of acylated tRNAs in vivo, our results are not in contrast with those previously reported by Berlani et al. 


\section{Francisci et al.}

A

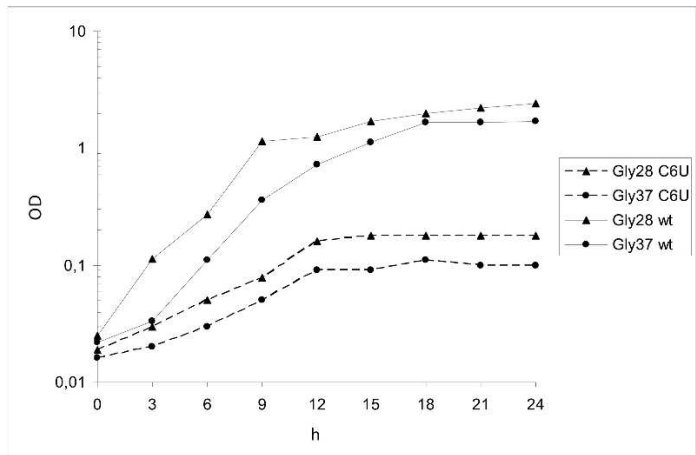

C

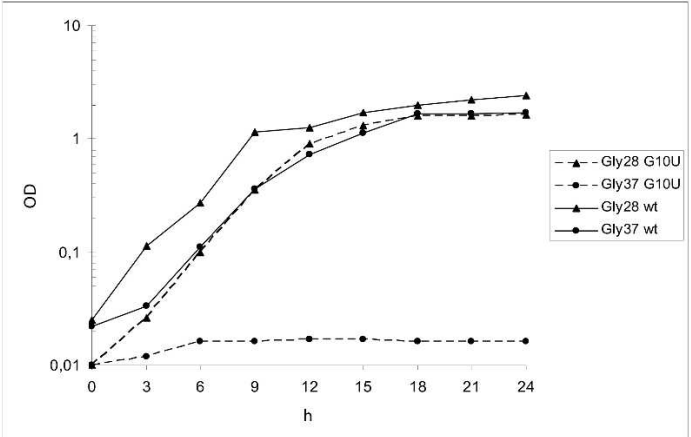

E

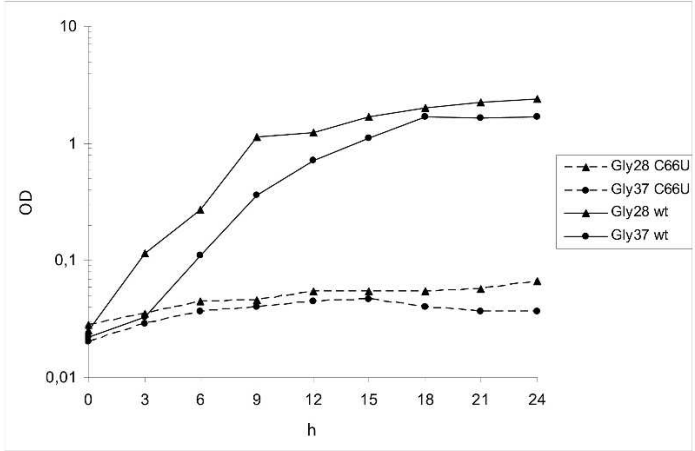

G

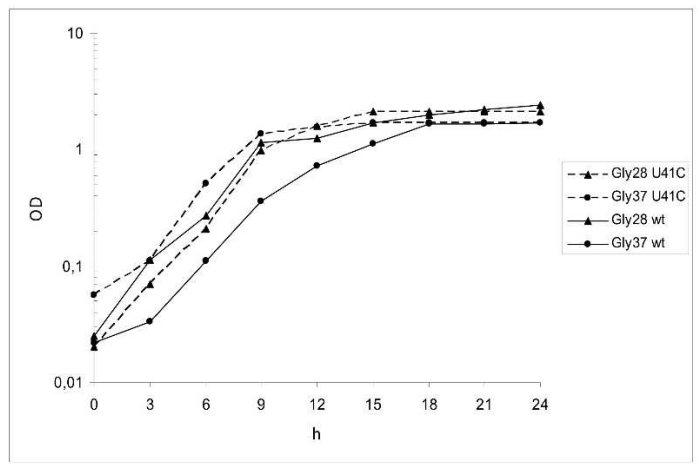

B

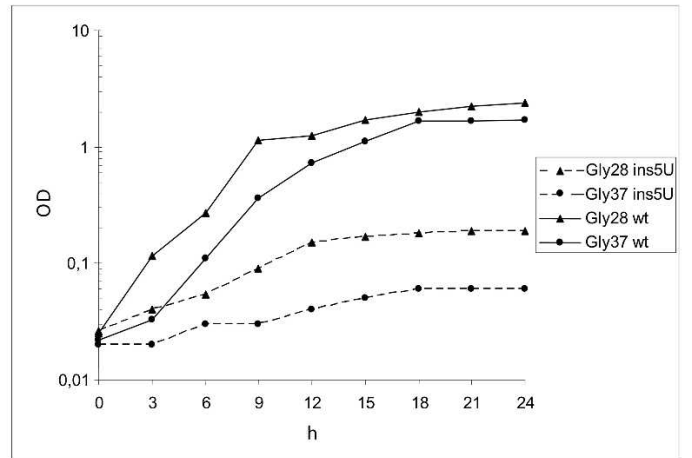

D

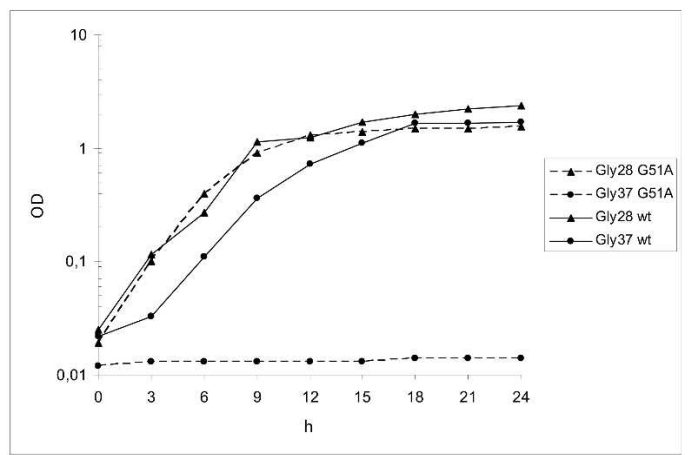

F

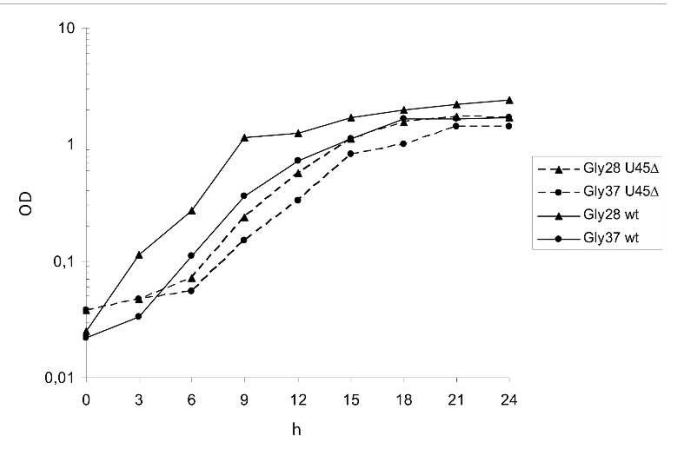

$\mathrm{H}$

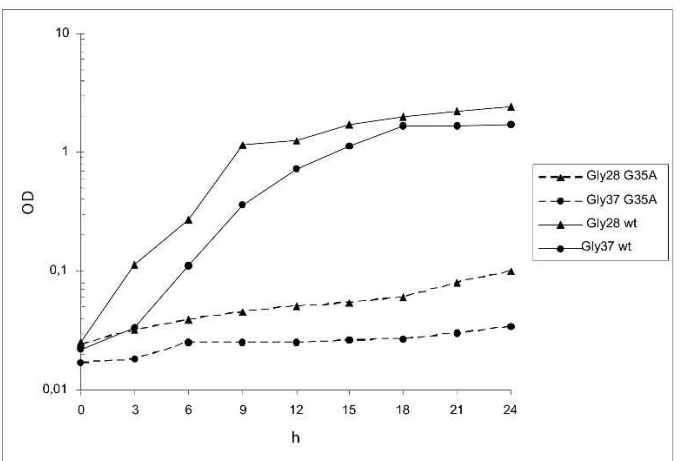

FIGURE 1. Growth curve of each mutant (broken line) followed for $24 \mathrm{~h}$ on glycerol-containing medium at $28^{\circ} \mathrm{C}(\boldsymbol{\Delta})$ and $37^{\circ} \mathrm{C}(\bullet)$ compared with the growth curve of the wild type (solid line). (A) C6U mutant; (B) ins5U mutant; $(C)$ G10U mutant; (D) G51A mutant; (E) C66U mutant; (F) U45 $\Delta$ mutant; (G) U41C mutant; (H) G36A mutant. 
TABLE 1. Analyzed mutations of yeast mitochondrial tRNAs

\begin{tabular}{|c|c|c|c|c|}
\hline \multirow[b]{2}{*}{ Mutants } & \multirow{2}{*}{$\begin{array}{l}\text { Localization of } \\
\text { the mutation }\end{array}$} & \multicolumn{2}{|c|}{ Glycerol growth } & \multirow[b]{2}{*}{ Reference } \\
\hline & & $28^{\circ} \mathrm{C}$ & $37^{\circ} \mathrm{C}$ & \\
\hline C6U & tRNA $^{\text {Gln }}$ AAstem & $+1-$ & $+/-$ & This work \\
\hline ins5U & tRNA $^{\text {Gln }}$ AAstem & $+1-$ & - & This work \\
\hline G10U & tRNA $^{\text {Gln }}$ Dstem & + & - & This work \\
\hline G51A & $\begin{array}{l}\text { tRNA }^{\mathrm{His}}(\mathrm{G} 50 \mathrm{~A}) \\
\text { Tstem }\end{array}$ & + & - & $\begin{array}{l}\text { Berlani et al. } 1980 \\
\text { This work }\end{array}$ \\
\hline C66U & $\begin{array}{l}\text { tRNA }{ }^{\text {Cys }} \\
\text { AAstem }\end{array}$ & - & - & $\begin{array}{l}\text { Berlani et al. } 1980 \\
\text { This work }\end{array}$ \\
\hline U45 & $\begin{array}{l}\text { tRNA }{ }^{\text {Arg2 }}(U 44 \Delta) \\
\text { Vloop }\end{array}$ & $+1-$ & $+/-$ & This work \\
\hline G36A & $\begin{array}{l}\text { tRNA }{ }^{\text {Arg2 }}(\mathrm{G} 35 \mathrm{~A}) \\
\text { ACloop }\end{array}$ & - & - & This work \\
\hline U41C & $\begin{array}{l}\text { tRNA }{ }^{\text {Ile }}(\mathrm{U} 42 \mathrm{C}) \\
\text { ACstem }\end{array}$ & + & + & This work \\
\hline
\end{tabular}

Mutants are indicated by their mutation type and position, according to the standard tRNA numbering (Sprinzl et al. 1998). Whenever the standard numbering differs from the specific tRNA sequence numbering, the latter is reported in the second column. We defined the glycerol growth as absent $(-)$, slow $(+/-)$ or normal $(+)$ (compared with the wild-type growth).

(1980), who did not find acylated-tRNA in RPC-5 histidyl tRNA chromatograms. The absence of acylated tRNA ${ }^{\text {His }}$ observed in the in vitro acylation experiment may be, at least partially, determined by reactions occurring during extraction procedures. Moreover, the different migration

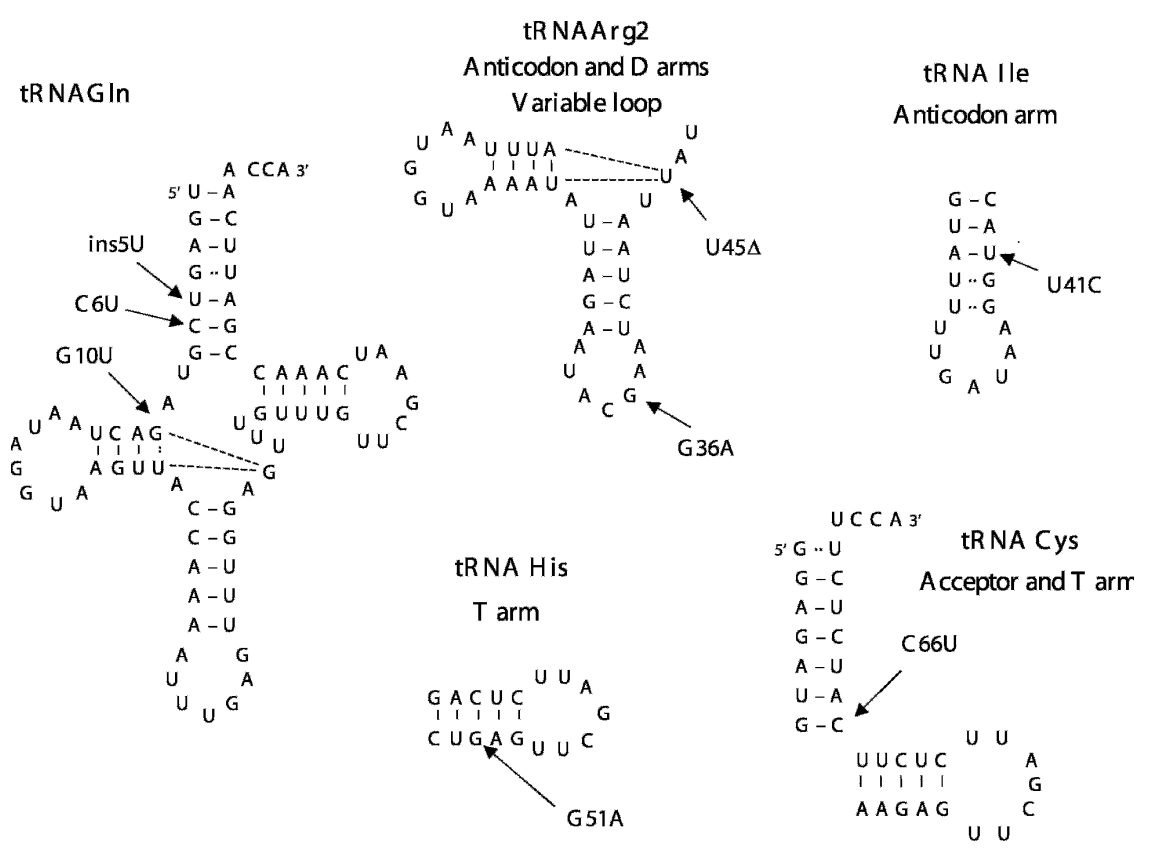

FIGURE 2. Location of the studied mutations in the context of tRNA secondary structure. The nucleotide sequence (mapped onto a cloverleaf diagram) of the $\mathrm{tRNA}^{\mathrm{Gln}}$ is reported (left), together with the sequences of the domains interested by the mutations, the T arm of tRNA ${ }^{\text {His }}$, the anticodon and D arms and the V loop of tRNA ${ }^{\text {Arg2 }}$, the anticodon arm of tRNA ${ }^{\text {Ile }}$, and the acceptor-stem and T arm of tRNA ${ }^{\text {Cys }}$. The mutated positions, indicated with arrows, are labeled according to the standard numbering (Sprinzl et al. 1998) referring to yeast cytoplasmic tRNA ${ }^{\text {Phe }}$. of the mutated molecule suggests that its conformation is likely to differ from that of the wild-type molecule in these conditions (Fig. 4C).

\section{Mutants G36A and U45D of $t R N A^{\text {Arg2 }}$}

The deacylation treatment of the sample extracted from wild type had a limited effect on the tRNA ${ }^{\text {Arg2 }}$ electrophoretic mobility (Fig. 5A,B); the faint faster-migrating band observed after the alkaline treatment is difficult to interpret, and may be a consequence of a partial deacylation or of a fragmentation of the tRNA ${ }^{\text {Arg2 }}$. The electrophoretic mobility of mature G36A tRNA ${ }^{\mathrm{Arg} 2}$ (Fig. 5A) obtained after the deacylation treatment (Fig. 5A, lanes De) have a pattern similar to that of wild type, indicating that the mutated tRNA does not undergo major structural distorsions in these conditions; however, comparison of tRNA $^{\mathrm{Arg} 2}$ hybridization signals obtained after the deacylation treatment (Fig. 5A, lanes De) shows that the mutated tRNA extracted from cells grown at $37^{\circ} \mathrm{C}$ is the most sensitive to the alkaline treatment (compared with that at $28^{\circ} \mathrm{C}$ and to the wild type), suggesting that the defective phenotype of G36A cells may be due to an unstable acylation state of the tRNA ${ }^{\text {Arg2 }}$. The mutated molecule from mutant $\mathrm{U} 45 \Delta$ presents a slightly faster migration compared with the wild-type $\mathrm{tRNA}^{\mathrm{Arg} 2}$ (Fig. 5B), thus confirming the presence of the deletion and pointing to a possible misfolding of the mutated molecule. Moreover, the faint faster-migrating band is not present in the deacylated samples of this mutant, probably indicating that the tRNA ${ }^{\mathrm{Arg} 2}$ is completely deacylated. Interestingly, aminoacyl-tRNA ${ }^{\text {Arg2 }}$ could only be detected when loading on the gels 10-fold the amount required for all other RNAs. Together with the low frequency of occurrence of the Arg2 codons in the yeast mtDNA (8.6 per thousand, compared with the 17.1 Arg1 codon frequency, analyzed by the Countcodon program www.kazusa.or.jp), this observation suggests that the tRNA ${ }^{\mathrm{Arg} 2}$ is the least transcribed of the two yeast $\mathrm{mt}$ genes coding for tRNA ${ }^{\mathrm{Arg}}$.

\section{Mutants C66U of $t R N A^{C y s}$ and $\cup 41 C$ of $t R N A^{\text {lle }}$}

For mutant C66U (Fig. 5C), we observed a defect in aminoacylation, indicated by the similar electrophoretic migration of the alkaline treated and untreated samples (Fig. 5C, top panel). The aminoacylation defect is specific for tRNA ${ }^{\text {Cys }}$, because no defect is observed in the same RNAs preparation with the 


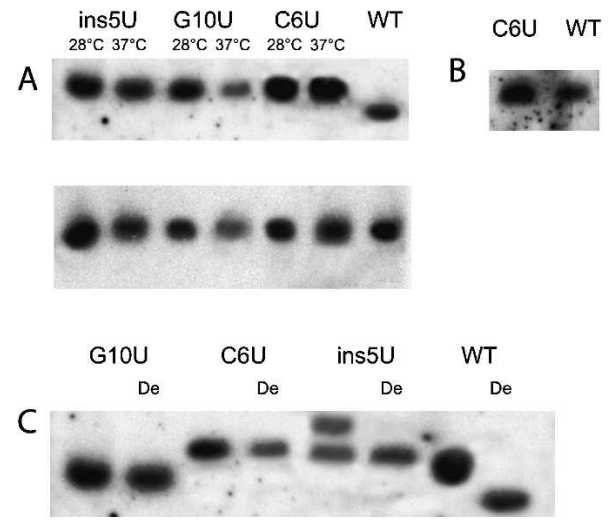

FIGURE 3. Northern blot analysis of mitochondrial transcripts, i.e., total RNAs extracted from purified mitochondria isolated from the indicated tRNA ${ }^{\mathrm{Gln}}$ mutant or wild-type strains and fractionated on partially $(A, C)$ or totally denaturing $(B)$ acrylamide-urea gels. Hybridization was with the $5^{\prime}$-end-labeled tRNA ${ }^{\mathrm{Gln}}$-probe ( $A$, top panel; $B ; C)$ or with the $5^{\prime}$-end-labeled tRNA ${ }^{\text {Gly }}$-probe, as control $(A$, bottom panel). In $C$, mt RNAs were extracted under acidic conditions from cells grown at $28^{\circ} \mathrm{C}$ and $37^{\circ} \mathrm{C}$ and treated to deacylate the tRNAs (De) (see Matherials and Methods).

tRNA $^{\text {Gln }}$ probe (Fig. 5C, bottom panel). The mutated tRNA $^{\text {Cys }}$ presents a different electrophoretic mobility compared with the wild type (Fig. 5C, top panel), suggesting an alternate tRNA structure as well. In wild-type and in mutant U41C, both the acylated and deacylated forms of tRNA $^{\text {Ile }}$ were present (as already observed for tRNA ${ }^{\text {His }}$ ) and had the same electrophoretic mobility (data not shown), indicating that the two molecules had similar conformation and were equally recognized by the cognate aminoacyltRNA synthetase.

\section{tRNA sequence and structure analysis}

To rationalize the experimentally determined effects of the mutations, we performed an analysis of the available yeast tRNA sequences and three-dimensional tRNA structures.

The results of the analysis of yeast tRNA sequences are summarized in Table 2. Yeast mitochondrial tRNAs do not appear to deviate significantly from the well-conserved architecture observed in most organisms (Dirheimer et al. 1995) in the length of the different stems and loops and in the number of each type of base pairs that they contain.

The average number of WC and non-WC base pairs, mismatches, insertions, and deletions in the stem regions is also very similar between cytoplasmic and mitochondrial tRNAs. However, the WC base pairs are different; cytoplasmic tRNAs have a G-C/A-U base-pair ratio of about 2:1, whereas in mitochondrial tRNAs, this ratio is reversed (Table 2). Due to their decreased content of G-C pairs, yeast mitochondrial tRNAs should have a lower intrinsic thermodynamic stability than their cytosolic counterparts. This is similar to what happens in higher mammals. The sequences of these $\mathrm{mt}$ tRNAs differ significantly from canonical bacterial and cytoplasmic tRNAs. In particular, the tRNAs functioning in human mitochondria have been postulated to be less thermodynamically stable, as they generally contain higher numbers of mismatches and $\mathrm{AU}$ base pairs (Helm et al. 2000, Wittenhagen and Kelley 2003).

Because of the inferred structural similarity between yeast mitochondrial and cytoplasmic tRNAs (Table 2) and canonical tRNAs from other species (Bloomfield et al. 2000a), the available three-dimensional structures of cytoplasmic tRNAs can be used as templates to model the tertiary interactions occurring in yeast mitochondrial tRNAs. The location of the analyzed mutations in the context of the three-dimensional structure of yeast cytosolic tRNA ${ }^{\text {Asp }}$ (Westhof et al. 1988) is shown in Figure 6.

For each mutation, we analyzed the frequency of occurrence of the mutated nucleotides and of the resulting base pairings in wild-type yeast tRNA sequences, estimated the likelihood that the mutated nucleotides are compatible with canonical tertiary interactions, and verified whether they have been previously identified as identity nucleotides, i.e., nucleotides necessary for recognition by the cognate aminoacyl-tRNA synthetase (Giegé et al. 1998). Moreover, we analyzed the available threedimensional structures of tRNA complexes with the cognate aa-RS or EF-Tu determined with resolution of $3.3 \AA$ or better, to evaluate whether the mutations might affect the steady-state aminoacylation levels in vivo by impairing interactions with protein partners.

Given the high sequence identity (72\%) between Thermus aquaticus and yeast EF-Tu, and the fact that T. aquaticus EF-Tu binds Escherichia coli $\mathrm{tRNA}^{\mathrm{Cys}}$ (PDB

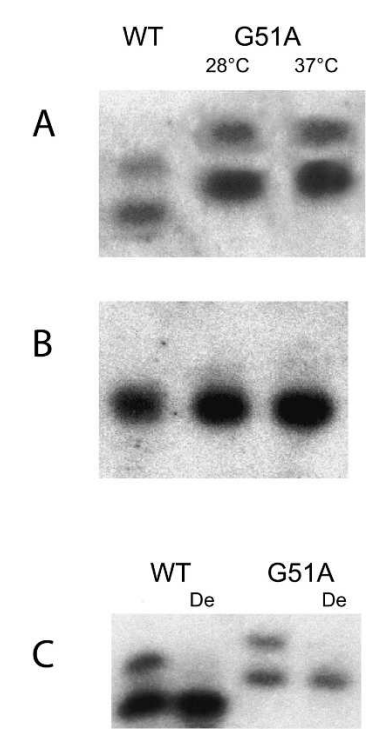

FIGURE 4. Northern blot analysis of mitochondrial transcripts. Total RNAs extracted acidically from purified mitochondria isolated from G51A mutant or wild-type strains and fractionated on acrylamide-urea gels. Hybridization was with the $5^{\prime}$-end labeled tRNA ${ }^{\mathrm{His}}$ probe $(A, C)$ or with the $5^{\prime}$-end labeled $m t$ tRNA ${ }^{\text {Cys }}$ probe as control $(B)$. In $C$, samples were deacylated as in Figure 3 (De). 

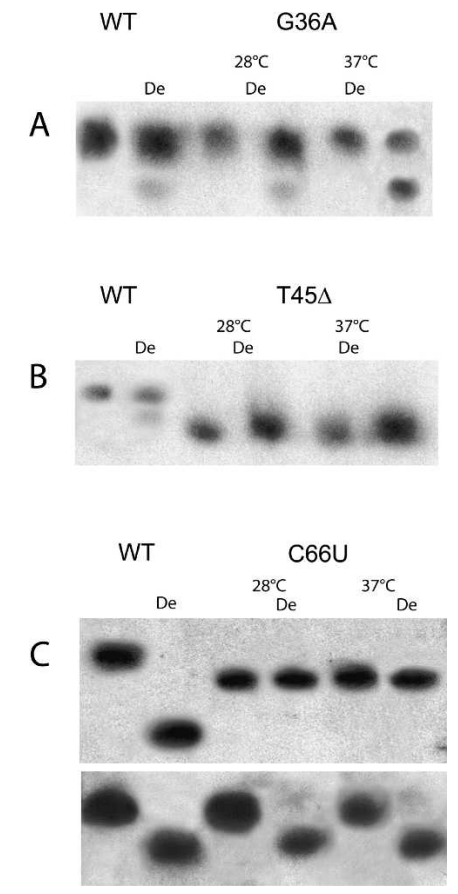

FIGURE 5. Northern blot analysis of mitochondrial transcripts. Total RNAs extracted from purified mitochondria isolated from the wild-type and from G36A $(A), \mathrm{U} 45 \Delta(B)$, and C66U $(C)$ mutants fractionated on acrylamide-urea gels. Mt RNAs were extracted under acidic conditions from mutant cells grown at $28^{\circ} \mathrm{C}$ or at $37^{\circ} \mathrm{C}$. Hybridization was with the $5^{\prime}$-end-labeled tRNA ${ }^{\mathrm{Arg} 2}$-probe $(A, B)$, with tRNA ${ }^{\mathrm{Cys}}$-probe $(C$, top), and with tRNA $^{\mathrm{Gln}}$-probe $(C$, bottom $)$ as control. Samples were deacylated as in Figure $3(\mathrm{De})$.

code: $1 \mathrm{~b} 23)$ and yeast $\mathrm{tRNA}^{\text {Phe }}$ (PDB code: $1 \mathrm{ttt}$ ) in essentially the same way, the interactions established between yeast tRNAs and EF-Tu are likely to be similar to those observed in the known structures, involving the AA stem and $\mathrm{T}$ arm (Fig. 7A).

The results of our frequency analysis for each of the mutated bases, the expected effect of the mutations on the tRNA secondary and tertiary structure, the role of these positions as identity nucleotides in other tRNA molecules, and/or their involvement in contacts with EF-Tu in known structures are reported in Table 3. Experimental results on the conformational and acylation properties of mutated tRNAs are summarized in the same table.

\section{DISCUSSION}

Previous studies have analyzed the consequences of point mutations in yeast mt tRNA genes that impair or abolish different aspects of tRNA functionality, and therefore the ability of the mutated strains to perform mitochondrial protein synthesis or to grow on glycerol medium (Berlani et al. 1980; Najarian et al. 1986; Francisci et al. 1998; Zennaro et al. 1998, Rohou et al. 2001; Feuermann et al. 2003). Among the most common effects, there are defects in maturation, stability, and aminoacylation. In order to identify the factors required for tRNA molecules to assume a correct three-dimensional structure and/or perform their function, we have studied the behavior of eight mutants of yeast mitochondrial tRNAs and of the respective wild-type tRNAs in partially denaturing gel conditions and after deacylation treatment.

We analyzed the available sequences of yeast mitochondrial and cytoplasmic tRNAs and the three-dimensional structures of cytoplasmic tRNAs to localize the mutations in the context of tRNA structure, and try to rationalize their effect on tRNA conformation and acylation state. As our analysis of tRNA sequences suggests that yeast mitochondrial tRNAs assume the canonical secondary and tertiary structures shared by the cytosolic tRNAs of most species (Bloomfield et al. 2000a), we could take advantage of the available three-dimensional structures of cytosolic tRNAs to model tertiary interactions occurring in yeast $\mathrm{mt}$ tRNAs.

Of the eight studied mutations, the five occurring in the $\mathrm{AA}$ and D stems and in the V loop (see Table 1; Fig. 2) cause both conformational and acylation defects. The substitution in the $\mathrm{T}$ stem shows only conformational defect. Mutants with substitutions in the AC arm show no acylation defect, with the only exception the G36A mutant grown at $37^{\circ} \mathrm{C}$, where a marginal effect on acylation could be detected.

\section{AA stem}

The conformational defects caused by the two substitutions (C6U of tRNA ${ }^{\text {Gln }}$ and C66U of tRNA ${ }^{\text {Cys }}$ ) occurring in the AA stem might be due to the replacement of base pairs in the stem regions with less stable and/or less frequently observed pairs (see Table 3). The insertion at position 5 of tRNA ${ }^{\mathrm{Gln}}$ might introduce a distorsion in the AA helix (especially since the adjacent pair is the non-WC base-pair G4U69).

The effect of these three mutations on the aminoacylation state of the tRNA molecules can be either due to a partial misfolding of the tRNA molecule and/or to the loss of specific tRNA interactions with proteins affecting the steady-state levels of acylated tRNA, like aa-RS or EF-Tu (see Table 3). Indeed, most identity nucleotides experimentally identified to date and tRNA positions in contact with synthetase residues in known structures are located in the AA and AC arms (Giegé et al. 1998), and nucleotides at positions 5,6 , and 66 are likely to affect the interactions with EF-Tu (see Fig. 7A; Table 3). Additionally, several lines of evidence indicate that the presence of identity nucleotides can be sufficient for recognition by aminoacyl-tRNA synthetases in the absence of a complete L-shape arrangement, and even in the case of some "reduced" tRNA structures, missing entire tRNA loops or stems. On the other hand, it is also known that specific architectural 
TABLE 2. Statistical analysis of yeast tRNA sequences

\begin{tabular}{|c|c|c|c|c|c|c|c|c|c|c|c|c|}
\hline \multirow[b]{2}{*}{ Length } & \multicolumn{4}{|c|}{ All sequences } & \multicolumn{4}{|c|}{ Cytoplasmic sequences } & \multicolumn{4}{|c|}{ Mitochondrial sequences } \\
\hline & Ave. & STD & Min. & Max. & Ave. & STD & Min. & Max. & Ave. & STD & Min. & Max \\
\hline Whole sequence & 76 & 5 & 71 & 90 & 75 & 4 & 71 & 87 & 76 & 6 & 71 & 90 \\
\hline Start & 0 & 0 & 0 & 1 & 0 & 0 & 0 & 1 & 0 & 0 & 0 & 1 \\
\hline AA stem & 14 & 0 & 14 & 14 & 14 & 0 & 14 & 14 & 14 & 0 & 14 & 14 \\
\hline Connector 1 & 2 & 0 & 2 & 2 & 2 & 0 & 2 & 2 & 2 & 0 & 2 & 2 \\
\hline D stem & 8 & 0 & 7 & 8 & 8 & 0 & 8 & 8 & 8 & 0 & 7 & 8 \\
\hline D loop & 8 & 1 & 7 & 11 & 8 & 1 & 7 & 10 & 8 & 1 & 7 & 11 \\
\hline AC stem & 12 & 0 & 11 & 13 & 12 & 0 & 11 & 12 & 12 & 0 & 12 & 13 \\
\hline AC loop & 7 & 0 & 7 & 8 & 7 & 0 & 7 & 7 & 7 & 0 & 7 & 8 \\
\hline V loop & 5 & 4 & 2 & 17 & 5 & 3 & 2 & 15 & 6 & 5 & 3 & 17 \\
\hline T stem & 10 & 0 & 10 & 11 & 10 & 0 & 10 & 10 & 10 & 0 & 10 & 11 \\
\hline T loop & 7 & 0 & 5 & 7 & 7 & 0 & 7 & 7 & 7 & 0 & 5 & 7 \\
\hline \multirow[t]{2}{*}{ Type of bps } & \multicolumn{4}{|c|}{ All sequences } & \multicolumn{4}{|c|}{ Cytoplasmic sequences } & \multicolumn{4}{|c|}{ Mitochondrial sequences } \\
\hline & Ave. & STD & Min. & Max. & Ave. & STD & Min. & Max. & Ave. & STD & Min. & Max \\
\hline \multicolumn{13}{|l|}{ Whole sequence } \\
\hline WC & 19 & 1 & 17 & 22 & 19 & 1 & 17 & 21 & 19 & 1 & 17 & 22 \\
\hline G-C & 11 & 3 & 4 & 18 & 13 & 2 & 10 & 18 & 7 & 2 & 4 & 10 \\
\hline A-T/U & 8 & 3 & 2 & 18 & 6 & 2 & 2 & 8 & 12 & 2 & 9 & 18 \\
\hline Non-WC & 3 & 2 & 0 & 8 & 3 & 2 & 0 & 8 & 3 & 2 & 0 & 8 \\
\hline Pur-pur/Pyr-pyr & 3 & 2 & 0 & 6 & 3 & 1 & 0 & 6 & 2 & 2 & 0 & 6 \\
\hline Insertions & 0 & 0 & 0 & 1 & 0 & 0 & 0 & 0 & 0 & 0 & 0 & 1 \\
\hline Deletions & 0 & 0 & 0 & 1 & 0 & 0 & 0 & 1 & 0 & 0 & 0 & 1 \\
\hline \multicolumn{13}{|l|}{ AA stem } \\
\hline WC & 6 & 1 & 4 & 7 & 6 & 1 & 4 & 7 & 6 & 1 & 5 & 7 \\
\hline $\mathrm{G}-\mathrm{C}$ & 3 & 1 & 1 & 6 & 4 & 1 & 2 & 6 & 2 & 1 & 1 & 4 \\
\hline$A-T / U$ & 3 & 1 & 0 & 6 & 2 & 1 & 0 & 4 & 4 & 1 & 2 & 6 \\
\hline Non-WC & 1 & 1 & 0 & 3 & 1 & 1 & 0 & 3 & 1 & 1 & 0 & 2 \\
\hline Pur-pur/Pyr-pyr & 0 & 0 & 0 & 1 & 0 & 0 & 0 & 1 & 0 & 0 & 0 & 1 \\
\hline Insertions & 0 & 0 & 0 & 0 & 0 & 0 & 0 & 0 & 0 & 0 & 0 & 0 \\
\hline Deletions & 0 & 0 & 0 & 0 & 0 & 0 & 0 & 0 & 0 & 0 & 0 & 0 \\
\hline \multicolumn{13}{|l|}{ D stem } \\
\hline WC & 3 & 1 & 2 & 4 & 3 & 1 & 2 & 4 & 4 & 1 & 2 & 4 \\
\hline G-C & 2 & 1 & 0 & 4 & 3 & 1 & 0 & 4 & 1 & 1 & 0 & 3 \\
\hline$A-T / U$ & 1 & 1 & 0 & 4 & 1 & 1 & 0 & 3 & 2 & 1 & 0 & 4 \\
\hline Non-WC & 0 & 0 & 0 & 2 & 0 & 0 & 0 & 2 & 0 & 0 & 0 & 1 \\
\hline Pur-pur/Pyr-pyr & 0 & 1 & 0 & 2 & 1 & 1 & 0 & 2 & 0 & 0 & 0 & 1 \\
\hline Insertions & 0 & 0 & 0 & 0 & 0 & 0 & 0 & 0 & 0 & 0 & 0 & 0 \\
\hline Deletions & 0 & 0 & 0 & 1 & 0 & 0 & 0 & 0 & 0 & 0 & 0 & 1 \\
\hline \multicolumn{13}{|l|}{ AC stem } \\
\hline WC & 5 & 1 & 3 & 6 & 5 & 1 & 3 & 6 & 5 & 1 & 3 & 6 \\
\hline G-C & 2 & 1 & 0 & 5 & 3 & 1 & 1 & 5 & 1 & 1 & 0 & 3 \\
\hline$A-T / U$ & 2 & 1 & 0 & 5 & 2 & 1 & 0 & 4 & 3 & 1 & 1 & 5 \\
\hline Non-WC & 1 & 1 & 0 & 2 & 0 & 1 & 0 & 2 & 1 & 1 & 0 & 2 \\
\hline Pur-pur/Pyr-pyr & 1 & 1 & 0 & 2 & 1 & 1 & 0 & 2 & 1 & 1 & 0 & 2 \\
\hline Insertions & 0 & 0 & 0 & 0 & 0 & 0 & 0 & 0 & 0 & 0 & 0 & 0 \\
\hline Deletions & 0 & 0 & 0 & 1 & 0 & 0 & 0 & 1 & 0 & 0 & 0 & 1 \\
\hline \multicolumn{13}{|l|}{ T stem } \\
\hline WC & 5 & 0 & 3 & 5 & 5 & 0 & 3 & 5 & 5 & 0 & 4 & 5 \\
\hline G-C & 3 & 1 & 1 & 5 & 4 & 1 & 2 & 5 & 2 & 1 & 1 & 4 \\
\hline$A-T / U$ & 1 & 1 & 0 & 3 & 1 & 1 & 0 & 3 & 2 & 1 & 0 & 3 \\
\hline Non-WC & 0 & 0 & 0 & 1 & 0 & 0 & 0 & 1 & 0 & 0 & 0 & 1 \\
\hline Pur-pur/Pyr-pyr & 0 & 0 & 0 & 2 & 0 & 0 & 0 & 2 & 0 & 0 & 0 & 1 \\
\hline Insertions & 0 & 0 & 0 & 1 & 0 & 0 & 0 & 0 & 0 & 0 & 0 & 1 \\
\hline Deletions & 0 & 0 & 0 & 1 & 0 & 0 & 0 & 0 & 0 & 0 & 0 & 1 \\
\hline
\end{tabular}

(Ave.) Average; (STD) standard deviation; (Min.) minimum value; (Max.) maximum value. 

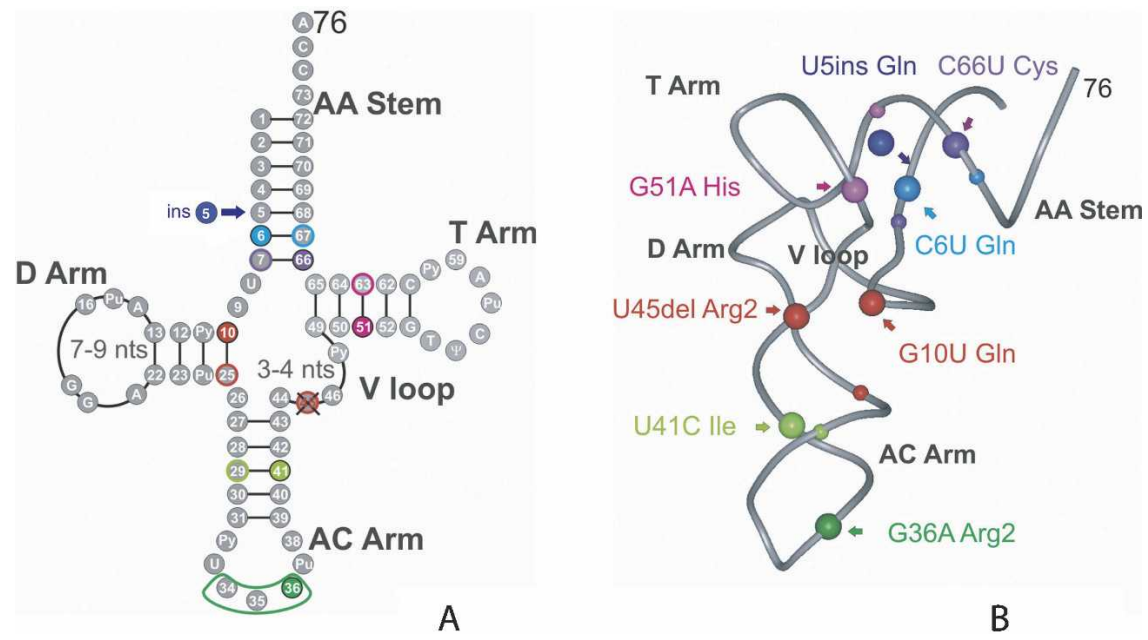

FIGURE 6. Mapping of the eight mutations described in this work on the secondary structure scheme of a tRNA molecule $(A)$, and on the three-dimensional structure of yeast cytosolic tRNA $^{\text {Asp }}(B)$ (Westhof et al. 1988). In $A$, the standard numbering (Sprinzl et al. 1998) and the conserved nucleotides (Bloomfield et al. 2000a) are shown (in yeast mt tRNAs, a few exceptions are observed at positions $14,15,21,32$, and 48 , and one at 55). Mutated positions are shown as color-filled circles and positions interacting with them are circled with the same color. In $B$, mutated positions are shown as large spheres centered on the $\mathrm{P}$ atoms and positions interacting with them as small spheres. The color coding is the same as in $A$.

that a conformational effect due to misfolding of the tRNA structure cannot be excluded.

\section{T stem}

The mutation G51A of tRNA ${ }^{\text {His }}$ determines different migration in partially denaturing gel conditions with respect to the wild-type molecule, but no defect in aminoacylation. Following this substitution, the highly stable G-C pair at positions $51-63$ of the $T$ stem is replaced by an A-C mispair, which is never observed at those positions in yeast tRNAs (see Table 3). The T loop, located at the end of the $\mathrm{T}$ stem, plays a crucial role in the establishment of the tertiary interactions determining the threedimensional arrangement of tRNAs. Distorsions of the $\mathrm{T}$ stem could affect these interactions and the whole structure of the tRNA molecule, and might therefore be the cause of the misfolding

features can be identity elements for some tRNAs (Giegé et al. 1998), and the lower thermodynamic stability of mitochondrial tRNAs might make them more sensitive to single-base mutations than their cytoplasmic counterparts. Therefore, it cannot be excluded that distorsions in the tRNA secondary structure and loss of conserved tertiary interactions might produce three-dimensional shapes which deviate from those optimized to interact with their cognate proteins, including aminoacyl-tRNA synthetases and/or EF-Tu.

\section{D stem}

The substitution occurring at position 10 of $\mathrm{tRNA}^{\mathrm{Gln}}$ determines the replacement of a G-U pair with the less stable U-U mismatch, which is never observed at position 10-25 in yeast tRNA sequences (see Table 3), and only three base pairs are left to form the D stem structure (Fig. 2). Furthermore, G10 is involved in conserved tertiary interactions with the guanosine at position 45 , located in the $\mathrm{V}$ loop. The nucleotide (nt) 10 is not in contact with EF-Tu (Fig. 7; Table 3), but the guanine at this position and its base-pair partner at position 25 are identity elements for yeast cytoplasmic tRNA $^{\text {Asp }}$ (Putz et al. 1991, 1993; Giegé et al. 1998) and T. thermophilus tRNA Gly (Giegé et al. 1998). Moreover, G10 is an identity nucleotide for E. coli tRNA ${ }^{\text {Gln }}$ and for E. coli and T. thermophilus tRNA ${ }^{\text {Asp }}$ (Giegé et al. 1998). Although this suggests that G10 might be an identity nucleotide for mt yeast $\mathrm{tRNA}^{\mathrm{Gln}}$ as well, the behavior of this mutant in partially denaturing gel conditions indicates observed for this mutant. However, the observed acylation of this molecule indicates that neither the conformational change caused by this substitution or the possible loss of the interactions between the nucleotide at position 51 and EF-Tu observed in the known structures (see Fig. 7A; Table 3) prevent recognition by the cognate proteins. Consequently, nt 51 is not an identity element of yeast $m t t_{R N A}{ }^{\text {His }}$, as well as of other tRNAs (Giegé et al. 1998).

\section{AC stem}

The mutation U41C of tRNA ${ }^{\text {Ile }}$ does not show either conformational or acylation defects, in agreement with the absence of a defective glycerol growth phenotype observed (see Fig. 1). The lack of effects on the tRNA acylation state indicates that position 41 is neither an identity nucleotide for yeast mitochondrial tRNA ${ }^{\text {Ile }}$ or necessary for recognition by EF-Tu, in agreement with the lack of contacts with this protein in the known structures (see Fig. 7A).

\section{AC loop}

Nucleotide G36 of $\mathrm{tRNA}^{\mathrm{Arg} 2}$ is located in the AC loop, which is highly variable in the analyzed tRNA structures, so that mutations in its bases are not expected to affect either the secondary or tertiary structure of tRNAs. However, several data indicate that the anticodon (positions 34-36) plays a crucial role in the selection of tRNAs by aminoacyltRNA synthetases (Rould et al. 1991; Li et al. 1993) and, as discussed above, positions 36 and 35 are known identity nucleotides for yeast cytoplasmic tRNA ${ }^{\text {Arg }}$ (Fig. 7B). These 
A

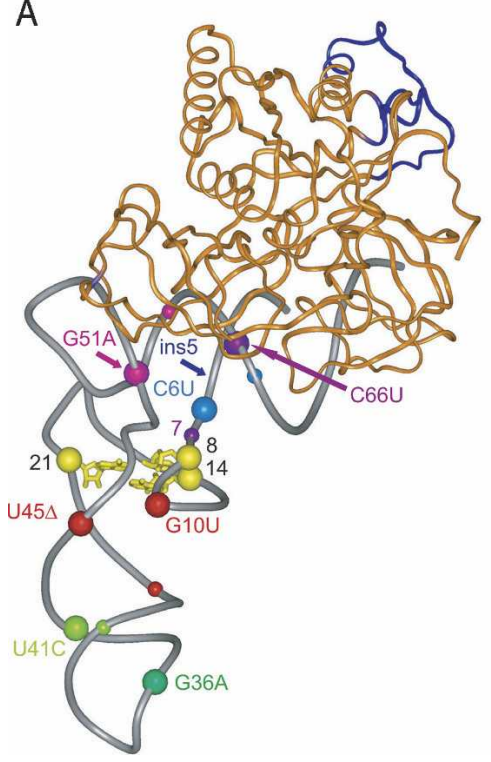

B

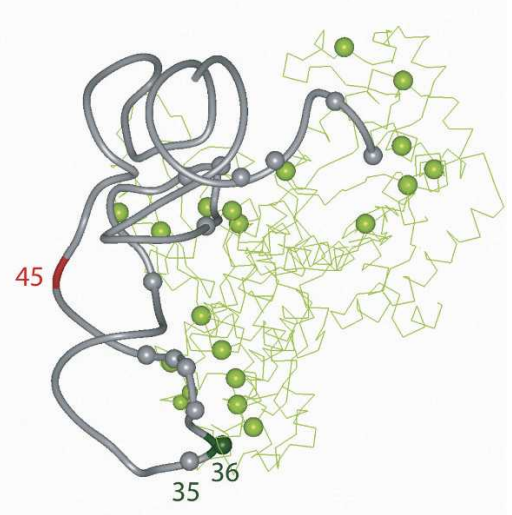

FIGURE 7. EF-Tu and synthetase contact with tRNA molecule. (A) Ribbon representation of yeast tRNA $^{\text {Phe }}$ in complex with Thermus aquaticus EF-Tu (Nissen et al. 1995). Mutated positions and their base-pair partners are shown as spheres centered on the $\mathrm{P}$ atom and colored as in Figure 6. The bases of nucleotides involved in the tertiary interaction 8-14-21 are shown as yellow sticks, and their P atoms as large yellow spheres. EF-Tu is orange, except those regions where the sequence alignment indicates the occurrence of insertions and/or deletions with respect to the yeast homolog (data not shown), which are blue. (B) Structure of the cytoplasmic yeast tRNA ${ }^{\mathrm{Arg}}$ in complex with the cognate synthetase (Delagoutte et al. 2000). The tRNA is shown as ribbon following its phosphate atoms and the protein as C $\alpha$ trace. The tRNA and protein structures are colored gray and green, respectively, and nucleotides and amino acids involved in intermolecular $\mathrm{H}$-bonds are shown as color-filled spheres. The two known tRNA identity determinants (positions 35 and 36) are labeled together with the V loop nt 45 . Position 36 and 45 are color-coded as in Figure 6.

observations, together with the observed lack of contacts of this tRNA position with EF-Tu in the known structures, lead us to conclude that the nucleotide at position 36 is an identity nucleotide for $\mathrm{mt}$ tRNA ${ }^{\mathrm{Arg} 2}$, as well as for its cytoplasmic counterpart.

As far as tRNA ${ }^{\operatorname{Arg} 2}$ is concerned, it is worth mentioning that, among all studied wild-type aminoacyl-tRNAs, this is the only one which is not completely deacylated by the alkaline procedure, possibly as a consequence of the higher amount of RNA that it was necessary to treat and load on the gel to visualize the $\mathrm{RNNA}^{\mathrm{Arg} 2}$, or because for this particular molecule, our gel electrophoretic conditions are not appropriate to separate the acylated from the deacylated tRNA $^{\text {Arg2 }}$. We might even speculate that aminoacyltRNA $^{\text {Arg2 }}$ is more resistent to deacylation than the other tRNAs examined in this work, possibly to compensate for its low transcription level.

\section{V loop}

The deletion $\mathrm{U} 45 \Delta$ in the $\mathrm{V}$ loop of tRNA ${ }^{\mathrm{Arg} 2}$ is likely to have a significant effect on the L-shaped tertiary structure. The usual length of V loops in class I tRNAs is 3-4 nt, and can be much longer in the case of class II tRNAs (Brennan and Sundaralingam 1976). In canonical tRNAs (Giegé et al. 1998), three nucleotides from the $\mathrm{V}$ loop are involved in conserved tertiary interactions with the $\mathrm{D}$ arm; the nucleotides at positions 45 and 46 interact with the $10-25$ and 13-22 base pairs, respectively, and the conserved $\mathrm{C} 48$ gives a reversed Watson-Crick base pair (Bloomfield et al. 2000b) with G15. In a 2-nt-long $\mathrm{V}$ loop, one of these three canonical interactions would be lost. Additionally, the $\mathrm{V}$ loop is not involved in contacts with EF-Tu (see Fig. 7A) or in recognition by synthetases in the wide majority of analyzed tRNA molecules (Giegé et al. 1998), and position 45 is not known to be an identity element for yeast cytosolic tRNA ${ }^{\text {Arg }}$ or other tRNAs, nor it is ever in contact with synthetases in any of the available complex structures. As an example, the structure of the cytoplasmic yeast $\mathrm{tRNA}^{\mathrm{Arg}}$ in complex with the parent synthetase (Fig. 7B) shows that $n t 45$ is located in a region of the tRNA structure opposite to the enzyme-bound surface. The cytoplasmic and mitochondrial yeast arginyltRNA synthetases are highly homologous, sharing $60 \%$ sequence identity, and the known identity nucleotides (C35 and G36) in yeast cytoplasmic tRNA ${ }^{\mathrm{Arg}}$ are conserved in the mitochondrial tRNA ${ }^{\mathrm{Arg} 2}$, suggesting a similar mode of binding for the two molecular systems. Hence, the defect in the acylation state of this mutant is more likely to be determined by the distorsion of the tRNA ${ }^{\text {Arg2 }}$ tertiary structure caused by the deletion than to the loss of an identity determinant or of specific interactions with EF-Tu.

In summary, although none of the mutations studied in this work is located in a universally conserved position of the corresponding tRNA molecule (Fig. 6), most of them determine the loss of favorable secondary or tertiary interactions occurring with high frequency in wild-type yeast mitochondrial and cytoplasmic tRNA sequences (Table 3), which might be necessary for the assumption of a correct structure by the tRNA and/or for its ability to interact with the cognate proteins. According to the observed behavior in partially denaturing acrylamide gel, the tRNA structure is affected by mutations occurring in all regions of the tRNA molecule with the exception of the AC arm, in agreement with a functional rather than structural role of this region and with its lack of contacts with other regions of the tRNA molecule. 
TABLE 3. Effect on structure and acylation of the analysed mutations

\begin{tabular}{|c|c|c|c|c|c|c|c|c|}
\hline $\begin{array}{l}\text { Localization of } \\
\text { the mutation }\end{array}$ & $\begin{array}{c}\text { Structural } \\
\text { defect }\end{array}$ & $\begin{array}{c}\text { Acylation } \\
\text { defect }\end{array}$ & $\begin{array}{c}\text { Effect of the mutation } \\
\text { on tRNA secondary } \\
\text { structure }\end{array}$ & $\begin{array}{c}\text { Frequency in wt } \\
\text { yeast mitochondrial } \\
\text { tRNAs }\end{array}$ & $\begin{array}{c}\text { Frequency in wt } \\
\text { yeast cytoplasmic } \\
\text { tRNAs }\end{array}$ & $\begin{array}{c}\text { Involvement in } \\
\text { conserved tertiary } \\
\text { interactions }\end{array}$ & $\begin{array}{c}\text { Comparison with } \\
\text { known identity } \\
\text { nucleotides }\end{array}$ & $\begin{array}{c}\text { Contacts } \\
\text { with EF-Tu }\end{array}$ \\
\hline C6U tRNA ${ }^{\text {Gln }}$ & Yes & Yes & $\begin{array}{l}\text { Replacement of one } \\
\text { WC G-C bp with one } \\
\text { non-WC G-U bp in } \\
\text { the AA stem, resulting } \\
\text { in the presence of two } \\
\text { non-WC bps, at } \\
\text { positions 4-69 and } \\
6-67 \text { (see Fig. 2). }\end{array}$ & $\begin{array}{l}\text { Only two sequences } \\
\text { have a non-WC G-U } \\
\text { bp at positions 6-67. In } \\
\text { three sequences the AA } \\
\text { stem contains two } \\
\text { non-WC bp (at } \\
\text { positions } 2-71 \text { and } \\
7-66,1-72 \text { and } \\
2-71, \text { and 3-70 and } \\
4-69 \text {, respectively); } \\
\text { however, two non-WC } \\
\text { at positions } 4-69 \text { and } \\
6-67 \text { are never } \\
\text { observed. }\end{array}$ & $\begin{array}{l}\text { Ten sequences have a } \\
\text { non-WC G-U bp at } \\
\text { positions 6-67 (and } \\
\text { six sequences have } \\
\text { T-T/U-U mispairs). } \\
\text { Five of them have a } \\
\text { second non-WC G-U } \\
\text { bp at positions } 2 \text { (four } \\
\text { cases) and } 5 \text { (one } \\
\text { case). Two non-WC } \\
\text { bps at positions } 4-69 \\
\text { and 6-67 are never } \\
\text { observed. }\end{array}$ & $\begin{array}{l}\text { No direct } \\
\text { involvement. }\end{array}$ & $\begin{array}{l}\text { Not known as } \\
\text { an identity } \\
\text { element for } \\
\text { yeast cytosolic } \\
\text { tRNAs or any } \\
\text { other analyzed } \\
\text { tRNA } \\
\text { molecules. }\end{array}$ & $\begin{array}{l}\text { No direct contact } \\
\text { of position 6, but its } \\
\text { base-pair partner } \\
\text { (position 67) is } \\
\text { hydrogen- } \\
\text { bonded to EF-Tu } \\
\text { (see Fig. 7A). }\end{array}$ \\
\hline ins5 $U$ tRNA ${ }^{\mathrm{Gln}}$ & Yes & Partial & $\begin{array}{l}\text { Insertion in } \\
\text { the AA stem. }\end{array}$ & Never observed. & Never observed. & $\begin{array}{l}\text { No direct } \\
\text { involvement. }\end{array}$ & $\begin{array}{l}\text { Not known as an } \\
\text { identity element } \\
\text { for tRNAs. }\end{array}$ & $\begin{array}{l}\text { No direct contact, } \\
\text { but adjacent to bp } \\
6-67 \text {. }\end{array}$ \\
\hline G10U tRNA ${ }^{\text {Gln }}$ & Yes & Yes & $\begin{array}{l}\text { Replacement of one } \\
\text { non-WC G-U bp } \\
\text { with one } U-U \\
\text { mismatch at the } \\
\text { beginning of the D } \\
\text { stem (positions 10-25). }\end{array}$ & $\begin{array}{l}\text { No sequence has } \\
\text { T-T/U-U at positions } \\
10-25 \text { but two } \\
\text { sequences have G-T/ } \\
U \text { and one (tRNA }{ }^{\text {Ser1 }} \text { ) } \\
\text { has a deletion at } \\
\text { position } 10 .\end{array}$ & $\begin{array}{l}\text { Two sequences have } \\
\text { one pur-pur } \\
\text { mismatch at positions } \\
10-25, \text { while } 25 \\
\text { sequences have non } \\
\text { G-U mismatches at } \\
\text { different positions in } \\
\text { the } D \text { stem. }\end{array}$ & $\begin{array}{l}\text { G10 is involved in } \\
\text { tertiary interaction } \\
\text { with nucleotide } 45 \\
\text { in the } V \text { loop. }\end{array}$ & $\begin{array}{l}\text { Nucleotide } 10 \text { is } \\
\text { an identity } \\
\text { element for } \\
\text { yeast tRNA } \\
\text { and } E \text {. coli } \\
\text { tRNA } \\
\text { Gln }\end{array}$ & No contact. \\
\hline G51A tRNA ${ }^{\mathrm{His}}$ & Yes & No & $\begin{array}{l}\text { Replacement of one } \\
\text { WC G-C bp with one } \\
\text { non-WC A-C bp, } \\
\text { resulting in the intro- } \\
\text { duction of one non-WC } \\
\text { bp in the T stem. }\end{array}$ & $\begin{array}{l}\text { The A-C pair is never } \\
\text { observed at positions } \\
51-63 \text {. However, one } \\
\text { sequence has the } \\
\text { non-WC G-U pair at } \\
\text { position } 51 \text { and two } \\
\text { sequences have } \\
\text { insertions at position } \\
51 . \text { Non-WC G-T/U } \\
\text { bps, and C-T/U or } \\
\text { T-T/U-U mismatches } \\
\text { are found at positions } \\
49-65 \text { and } 50-64 \text { in } \\
\text { the T stem. }\end{array}$ & $\begin{array}{l}\text { The A-C pair is never } \\
\text { observed at positions } \\
51-63 \text {; however, } \\
\text { G-T/U and T-T/U-U } \\
\text { pairs are found at this } \\
\text { position (as well as at } \\
\text { positions } 49-65 \text {, } \\
50-64 \text {, and } 52-62 \text { ), } \\
\text { and A-C is found at } \\
\text { positions } 50-64 \text { and } \\
52-62 \text {. }\end{array}$ & $\begin{array}{l}\text { No direct } \\
\text { involvement, but the } \\
\text { T loop, at the end of } \\
\text { the T stem, estab- } \\
\text { lishes tertiary } \\
\text { interactions } \\
\text { necessary for tRNA } \\
\text { three-dimensional } \\
\text { arrangement. }\end{array}$ & $\begin{array}{l}\text { Not known as } \\
\text { an identity } \\
\text { element for } \\
\text { yeast cytosolic } \\
\text { tRNA }{ }^{\text {His }} \text { or } \\
\text { other tRNAs. }\end{array}$ & Yes (see Fig. 7A). \\
\hline
\end{tabular}


TABLE 3. Continued

\begin{tabular}{|c|c|c|c|c|c|c|c|c|}
\hline $\begin{array}{l}\text { Localization of } \\
\text { the mutation }\end{array}$ & $\begin{array}{c}\text { Structural } \\
\text { defect }\end{array}$ & $\begin{array}{l}\text { Acylation } \\
\text { defect }\end{array}$ & $\begin{array}{l}\text { Effect of the mutation } \\
\text { on tRNA secondary } \\
\text { structure }\end{array}$ & $\begin{array}{c}\text { Frequency in wt } \\
\text { yeast mitochondrial } \\
\text { tRNAs }\end{array}$ & $\begin{array}{l}\text { Frequency in wt } \\
\text { yeast cytoplasmic } \\
\text { tRNAs }\end{array}$ & $\begin{array}{l}\text { Involvement in } \\
\text { conserved tertiary } \\
\text { interactions }\end{array}$ & $\begin{array}{c}\text { Comparison with } \\
\text { known identity } \\
\text { nucleotides }\end{array}$ & $\begin{array}{l}\text { Contacts } \\
\text { with EF-Tu }\end{array}$ \\
\hline C66U tRNA ${ }^{\text {Cys }}$ & Yes & Yes & $\begin{array}{l}\text { Replacement of one } \\
\text { WC G-C bp with one } \\
\text { non-WC G-U bp in } \\
\text { the AA stem, resulting } \\
\text { in the presence of two } \\
\text { non-WC bps at posi- } \\
\text { tions } 1-72 \text { and } 7-66 \text {. }\end{array}$ & $\begin{array}{l}\text { Positions } 7-66 \text { are rarely } \\
\text { occupied by a non-WC } \\
\text { bp and are occupied } \\
\text { by G-U only in one } \\
\text { sequence. In three } \\
\text { sequences the AA stem } \\
\text { contains } 2 \text { non-WC bp } \\
\text { (at positions } 2-71 \text { and } \\
7-66,1-72 \text { and } 2-71, \\
\text { and 3-70 and } 4-69, \\
\text { respectively); however, } \\
\text { two non-WC at posi- } \\
\text { tions } 1-72 \text { and } 7-66 \\
\text { are never observed. }\end{array}$ & $\begin{array}{l}\text { No sequence has a } \\
\text { non-WC G-U bp at } \\
\text { positions } 7-66 \text {. }\end{array}$ & $\begin{array}{l}\text { No direct involvement, } \\
\text { but nucleotide U8, } \\
\text { adjacent to the 7-66 } \\
\text { bp, interacts with } \\
\text { bases } 14 \text { and } 21 \text { in } \\
\text { the } D \text { loop (see } \\
\text { Fig. 7). }\end{array}$ & $\begin{array}{l}\text { Not known as an } \\
\text { identity ele- } \\
\text { ment for yeast } \\
\text { cytosolic } \\
\text { tRNA }^{\text {Cys }} \text { or } \\
\text { other tRNAs. }\end{array}$ & Yes (see Fig. 7A). \\
\hline $\begin{array}{l}\text { U } 45 \Delta \\
\text { tRNA }\end{array}$ & Probable & Yes & $\begin{array}{l}\text { Shortening of } \vee \text { loop } \\
\text { from length } 3 \text { to } 2 .\end{array}$ & $\begin{array}{l}V \text { loops of length } 2 \text { are } \\
\text { never observed in } \\
\text { wild-type yeast } \mathrm{mt} \\
\text { tRNAs. }\end{array}$ & $\begin{array}{l}\text { A } \vee \text { loop of length } 2 \text { is } \\
\text { observed only in } \\
\text { tRNA }^{\mathrm{Gly} 1} \text {. This has } \\
\text { also } 21 \mathrm{WC} \text { bp, the } \\
\text { highest number of } \\
\text { WC in cytoplasmic } \\
\text { tRNAs. }\end{array}$ & $\begin{array}{l}\text { Tertiary interactions } \\
\text { with the } 10-25 \mathrm{bp} \\
\text { in canonical } \\
\text { tRNAs. }\end{array}$ & $\begin{array}{l}\text { Nucleotide } 45 \text { is } \\
\text { not an identity } \\
\text { element for } \\
\text { yeast cytosolic } \\
\text { tRNA }{ }^{\text {Arg }} \text { or } \\
\text { other tRNAs. }\end{array}$ & No contact. \\
\hline $\begin{array}{l}\text { G36A } \\
\text { tRNA }^{\text {Arg2 }}\end{array}$ & No & Probable & $\begin{array}{l}\text { Replacement of G with } \\
\mathrm{A} \text { in the anticodon, } \\
\text { resulting in the sub- } \\
\text { stitution of the ACG } \\
\text { triplet of the AC loop } \\
\text { with ACA, which is a } \\
\text { putative anticodon for } \\
\text { cysteine. }\end{array}$ & $\begin{array}{l}\text { The anticodon ACA is } \\
\text { never observed. }\end{array}$ & $\begin{array}{l}\text { The anticodon ACA } \\
\text { is never observed. }\end{array}$ & $\begin{array}{l}\text { No direct } \\
\text { involvement. }\end{array}$ & $\begin{array}{l}\text { G36 is an identity } \\
\text { element for } \\
\text { yeast cytosolic } \\
\text { tRNA }{ }^{\text {Arg }} \text {, and } \\
\text { positions 34-36 } \\
\text { are generally } \\
\text { identity } \\
\text { elements for } \\
\text { tRNAs. }\end{array}$ & No contact. \\
\hline U41C tRNA ${ }^{l l e}$ & No & No & $\begin{array}{l}\text { Replacement of the } \\
\text { A29-U41 WC bp } \\
\text { with one A-C mispair, } \\
\text { resulting in the pre- } \\
\text { sence of four non-WC } \\
\text { bps (positions 26-44, } \\
29-41,30-40 \text {, and } \\
31-39 \text { ) and only two } \\
\text { standard bps in the } \\
\text { AC stem. }\end{array}$ & $\begin{array}{l}\text { Very few sequences } \\
\text { have fewer than four } \\
\text { WC pairs in the AC } \\
\text { stem. Only tRNA } \\
\text { has three non-WC bps } \\
\text { in the AC stem (at } \\
\text { positions 26-44, 30- } \\
40 \text {, and 31-39), and } \\
\text { no mt tRNA has only } \\
\text { two. In no sequence } \\
\text { there is one non-WC } \\
\text { bp at position 29-41. }\end{array}$ & $\begin{array}{l}\text { Four non-WC bps are } \\
\text { never observed in the } \\
\text { AC stem of yeast wild- } \\
\text { type cytoplasmic } \\
\text { tRNAs. Only two } \\
\text { tRNAs have three } \\
\text { non-WC bps in the } \\
\text { AC stem (at positions } \\
26-44,29-41 \text {, and } \\
30-40 \text { ) and only } \\
\text { three sequences have } \\
\text { one non-WC bp at } \\
\text { positions } 29-41 \text { (two } \\
\text { AC and one purine- } \\
\text { purine). }\end{array}$ & $\begin{array}{l}\text { No direct } \\
\text { involvement. (The } \\
\text { AC arm does not } \\
\text { contact other tRNA } \\
\text { regions, and there- } \\
\text { fore it does not } \\
\text { affect its global } \\
\text { structure.) }\end{array}$ & 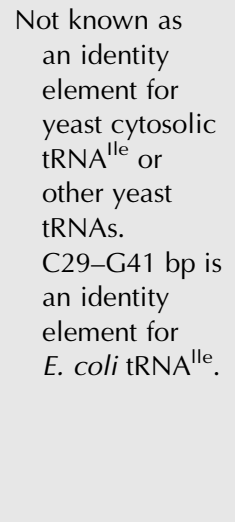 & No contact. \\
\hline
\end{tabular}

(Pyr) Pyrimidine; (pur) purine; (bp) base pair. 
The acylation state is affected by all of the studied mutations except those occurring in the $\mathrm{T}$ and $\mathrm{AC}$ stem, indicating that positions 51 and 41 are not identity nucleotides for yeast $m t \mathrm{tRNA}^{\mathrm{His}}$ and tRNA ${ }^{\text {Ile }}$, respectively, and do not take part in essential interactions with EF-Tu. Nucleotide 36 in the AC loop, whose mutation causes acylation but not structural defects, and which is not involved in interactions with $\mathrm{EF}-\mathrm{Tu}$, is likely to be an identity nucleotide for yeast mt tRNA ${ }^{\text {Arg2 }}$. Conversely, the acylation defect caused by the $\mathrm{U} 45$ deletion in yeast $\mathrm{mt}$ tRNA ${ }^{\mathrm{Arg} 2}$ is likely to be due to a partial misfolding of its structure.

The results presented in this work contribute to widening our current understanding of the yeast system and might provide the basis to derive more general rules on the sequence-structure function relationships in tRNA molecules, possibly applicable to mitochondrial as well as cytoplasmic tRNAs from other species.

\section{MATERIALS AND METHODS}

\section{Media and strains}

Strains were grown on complete medium ( $1 \%$ yeast extract and $1 \%$ peptone from Difco) containing $2 \%$ glucose or $3 \%$ glycerol. Media containing 2\% galactose were used to collect cells for $\mathrm{mt}$ nucleic acids preparation. Minimal medium was $0.17 \%$ yeast nitrogen base (DIFCO), $0.5 \%$ ammonium sulphate, and $2 \%$ glucose, supplemented with the necessary auxotrophic requirements. For plates, $2 \%$ agar was added to the medium.

Mutants were isolated by Berlani et al. (1980) from the wildtype strain D273-10B/A1 (MAT $\alpha$, met, rho $\left.{ }^{+}\right)$mutagenized with $\mathrm{MnCl}_{2}$. Nuclear mutants were eliminated by crossing with overlapping rho- tester strains, and the mutations located in the tRNA region were selected. For two strains (C66U and G51A) the mutated genes were identified by complementation with rhomutants retaining specific sections of the tRNA region (Berlani et al. 1980).

\section{Primers and probes}

The oligo 20-mer ( $5^{\prime}$-GAATCGGTTTGATTCGAACA-3') complementary to residues $51-70$ of the tRNA ${ }^{\mathrm{Gln}}$ gene $\left(\mathrm{GLN}^{-}\right)$, the 20-mer ( $5^{\prime}$-CGCACCACAAGCGTATTTTC- $\left.3^{\prime}\right)$ complementary to residues $22-41$ of the $\mathrm{tRNA}^{\mathrm{His}}$ gene $\left(\mathrm{HIS}^{-}\right)$, the 20 -mer $\left(5^{\prime}-\mathrm{GTA}\right.$ GATTTGCAATCTAATAG- $3^{\prime}$ ) complementary to residue 24-43 of the tRNA ${ }^{\mathrm{Cys}}$ gene $\left(\mathrm{CYS}^{-}\right)$, the 23 -mer $\left(5^{\prime}\right.$-CCTATATAATTA GATTCGTATTC-3') complementary to residues $29-51$ of the tRNA $^{\text {Arg2 }}$ gene $\left(\mathrm{ARG}^{-}\right)$, and the 19 -mer $\left(5^{\prime}\right.$-CCTATATTTG TACCTTATC- $\left.3^{\prime}\right)$ complementary to residues $25-53$ of the tRNA ${ }^{\text {Ile }}$ gene $\left(\mathrm{ILE}^{-}\right)$were $5^{\prime}$-end labeled as described in Saambrook et al. (1989) and used for Northern blot experiments.

The following primers were used for PCR amplification and sequencing of tRNA genes: for mutations C6T, ins5T, and G10T, mapping in the $\mathrm{tRNA}^{\mathrm{Gln}}$, primer $\mathrm{HIS}^{+}\left(5^{\prime}\right.$-GAAAA TACGCTTGTGGTG- $3^{\prime}$ ) located in the tRNA ${ }^{\text {His }}$ gene and primer LYS $^{-} \quad\left(5^{\prime}\right.$-GGGTTGCTTAAAAGACAACT- $\left.3^{\prime}\right)$ located in the tRNA $^{\text {Lys }}$ gene; for mutation G51A, mapping in the tRNA ${ }^{\text {His }}$, primer CYS $^{+}\left(5^{\prime}\right.$-CTATTAGATTGCAAATCTAC-3 $\left.3^{\prime}\right)$ located in the $\mathrm{tRNA}^{\mathrm{Cys}}$ gene and primer $\mathrm{GLN}^{-}$; for mutation C66T, mapping in the tRNA ${ }^{\text {Cys }}$, primer $\mathrm{THR}^{+}\left(5^{\prime}\right.$-GCATTCGTTTTG TAATCG- $3^{\prime}$ ) located in the $\mathrm{RRNA}^{\mathrm{Thr} 2}$ gene and primer $\mathrm{HIS}^{-}$; for mutation G36A, mapping in the $\mathrm{tRNA}^{\mathrm{Arg} 2}$, primer SER2 ${ }^{+}$ $\left(5^{\prime}\right.$-GGAAAATTAACTATAGGTAAAG- $\left.3^{\prime}\right)$ located in the tRNA ${ }^{\text {Ser2 }}$ gene and primer $\mathrm{ILE}^{-}$; for mutation T41C, mapping in the tRNA $^{\text {Ile }}$, primer GLY $^{+}$(5'-GGATGTCTTCCAAACATTGA- $\left.3^{\prime}\right)$ located in the $\mathrm{TRNA}^{\mathrm{Gly}}$ gene and primer $3^{\prime}$-TYR ${ }^{-}\left(5^{\prime}\right.$-CATTGGAT TATATTAATTTCAATGG-3') located downstream the tRNA ${ }^{\text {Tyr }}$ gene.

Sequences were determinated by Bio Molecular Research Sequencing Service-Padova (Applied Biosystems ABI PRISM 3730XL DNA Sequencer) and compared with the complete sequence reported by Foury et al. (1998).

\section{DNA and RNA manipulations}

DNA manipulation, restriction enzyme digestion, plasmid engineering, and other standard techniques were performed as described by Saambrook et al. (1989).

Mitochondrial DNA was isolated as "miniprep" from galactosegrowing cells as previously reported by Francisci et al. (1998). To determine whether the mutated tRNA genes are transcribed in vivo and whether transcripts are stable and correctly processed, RNAs were isolated from purified mitochondria of mutant and wild-type cells grown to mid-log phase in $2 \%$ galactose media at $28^{\circ} \mathrm{C}$. Since several mutants are temperature sensitive, mitochondria were also extracted after a shift to $37^{\circ} \mathrm{C}$. After $4 \mathrm{~h}$, cells were collected and purified mitochondria were prepared following the method of Faye et al. (1974). Mitochondrial RNAs were extracted in pH 7.5 buffer as described by Baldacci and Zennaro (1982).

To fractionate mt tRNAs, we used the $6 \%$ polyacrylamide- $8 \mathrm{M}$ urea sequencing gels $(40 \mathrm{~cm}$ in length). These gels can be partially denaturing (gel electrophoresis conducted in cold room) or completely denaturing (gel electrophoresis conducted at room temperature); they are the most informative gels used, in that they can distinguish a single-base insertion or deletion in tRNAs (Saambrook et al. 1989). We have previously shown (Rinaldi et al. 1994; Feuermann et al. 2003) that mutated tRNAs can have lower electrophoretic mobility than wild-type tRNAs in partially denaturing condition. Here, we show that this is not accompanied by a change in electrophoretic mobility in completely denaturing gels, and can therefore be ascribed to structure alteration. Sequencing gels were used to analyze tRNA aminoacylation according to the following procedure: $m t$ tRNAs were extracted from wild-type and mutant cells under acidic conditions $(\mathrm{pH} 5)$, subjected to alkaline treatment (incubation in $0.2 \mathrm{M}$ Tris- $\mathrm{HCl}$ at $\mathrm{pH} 8.8$ at $37^{\circ} \mathrm{C}$ for $90 \mathrm{~min}$ ) to hydrolyze the ester linkage between the tRNA and the cognate amino acid, and fractionated in $0.1 \mathrm{M}$ sodium acetate buffer $(\mathrm{pH}$ 5). In these acidic conditions, a different electophoretic migration between the mutant and wild-type tRNA molecules after the deacylation treatment is likely to be determined by their different conformation. On the other hand, a different electrophoretic migration between samples subjected or not to alkaline treatment is likely to occur only when RNAs extracted from the cells are correctly acylated. Electrophoresis and hybridization conditions were as reported by Varshney et al. (1991), with minor 
modifications. The tRNAs electrophoretic mobility was also tested on partially denaturing $1.5 \%$ agarose, $8 \mathrm{M}$ urea gels, or totally denaturing $1.5 \%$ agarose, formaldehyde $37 \% \mathrm{v} / \mathrm{v}$ (data not shown). About $10 \mu \mathrm{g}$ of RNA were loaded in each slot, as verified by comparison with the amount of ribosomal mt RNA on agarose TBE gel electrophoresis. To only visualize tRNA ${ }^{\text {Arg2 }}$ of both wild-type and mutated strains, it was necessary to load about $100 \mu \mathrm{g}$ RNA.

PCR reaction mixture and cycles for mt DNA amplification were carried out as described in Rohou et al. (2001).

\section{tRNA sequence and structure analysis}

We analyzed 91 nonredundant yeast tRNA sequences (61 from cytoplasm and 30 from mitochondria) downloaded from the "Compilation of tRNA sequences and sequences of tRNA genes (August 2003 edition)" (Sprinzl et al. 1998). For each sequence, we recorded the length of the stems of the loops and of the connector segments, the number of Watson and Crick (WC) base pairs, and the number of mismatches, insertions, and deletions in the stems.

Nineteen nonredundant structures of free tRNAs (PDB identifiers ([Ds]: 2tra, 1ehz, 1fir), tRNA-synthetase (aa-RS) complexes (PDB IDs: 1f7u, 1asz, 1il2, 1c0a, 1o0c, 1n78, 1ffy, 1eiy, 1h4s, 1qf6, 1h3e, 1ser, 1j1u, 1ivs) and tRNA-elongation factor Tu (EF-Tu) complexes (1ttt, 1b23) determined by X-ray crystallography at a resolution of $3.3 \AA$ or better were collected from the PDB data archive (Berman et al. 2000). Structure analysis was performed using the software InsightII (Dayringer et al. 1986). Using the set of tools available in the package, we analyzed hydrogen-bond patterns, contacts, and accessible surface areas for each of the structures. Models of the mutants were built by manually replacing individual nucleotides. The crystal structures of yeast cytosolic tRNA $^{\text {Asp }}$, PDB ID: 2tra (Westhof et al. 1998), of yeast cytosolic tRNA $^{\text {Phe }}$ in complex with EF-Tu, PDB ID: 1ttt (Nissen et al. 1995) and of yeast cytosolic tRNA ${ }^{\text {Arg }}$ in complex with the cognate arginyl-tRNA synthetase, PDB ID: 1f7u (Delagoutte et al. 2000) were used as templates.

\section{ACKNOWLEDGMENTS}

This work was supported by Telethon (GGP030240) and by University "La Sapienza" of Rome (C26A039249). R.O. gratefully acknowledges Accademia dei Lincei-Centro Linceo Interdisciplinare "Beniamino Segre" and Programma Strategico FIRB for support.

Received February 7, 2005; accepted March 24, 2005.

\section{REFERENCES}

Baldacci, G. and Zennaro, E. 1982. Mitochondrial transcripts in glucose-repressed cells of Saccharomyces cerevisiae. Eur. J. Biochem. 127: 411-416.

Berlani, E.R., Pentella, C., Macino, G., and Tzagoloff, A. 1980. Assembly of the mitochondrial membrane system: Isolation of mitochondrial transfer ribonucleic acid mutants and characterization of transfer ribonucleic acid genes of Saccharomyces cerevisiae. J. Bacteriol. 141: 1986-1097.

Berman, H.M., Westbrook, J., Feng, Z., Gilliland, G., Bhat, T.N., Weissig, H., Shindyalov, I.N., and Bourne, P.E. 2000. The Protein Data Bank. Nucleic Acids Res. 28: 235-242.
Bloomfield, V.A., Crothers, D.M., and Tinoco Jr., I. 2000a. Transfer RNA. In Nucleic acids: Structures, properties and functions, pp. 103-110. University Science Books, Sausalito, CA.

- 2000b. Base pairing and base stacking. In Nucleic acids: Structures, properties and functions, pp. 31-43, University Science Books, Sausalito, CA.

Brennan, T. and Sundaralingam, M. 1976. Structure of transfer RNA molecules containing the long variable loop. Nucleic Acids Res. 3: 3235-3250.

Dayringer, H.E., Tramontano, A., Sprang, S.R., and Fletterick, R.J. 1986. INSIGHT an interactive molecular graphics package. J. Mol. Graph 4: 82-87.

Delagoutte, B., Moras, D., and Cavarelli, J. 2000. tRNA aminoacylation by arginyl-tRNA synthetase: Induced conformations during substrates binding. EMBO J. 19: 5599-5610.

Dirheimer, G., Keith, G., Dumas, P., and Westhof, E. 1995. Primary, secondary and tertiary structures of tRNAs. In tRNA: Structure, biosynthesis, and function (eds. D. Söll and U. RajBhandary), pp. 93-126. American Society for Microbiology Press, Washington, DC.

Faye, G., Kujawa, C., and Fukuhara, H. 1974. Physical and genetic organization of petite and grande yeast mitochondrial DNA. In vivo transcription products of mitochondrial DNA and localization of $23 \mathrm{~S}$ ribosomal RNA in petite mutants of Saccharomyces cerevisiae. J. Mol. Biol. 88: 185-203.

Feuermann, M., Francisci, S., Rinaldi, T., De Luca, C., Rohou, H., Frontali, L., and Bolotin-Fukuhara, M. 2003. The yeast counterparts of human 'MELAS' mutations cause mitochondrial dysfunction that can be rescued by overexpression of the mitochondrial translation factor EF-Tu. EMBO Rep. 4: 53-58.

Foury, F., Roganti, T., Lecrenier, N., and Purnelle, B. 1998. The complete sequence of the mitochondrial genome of Saccharomyces cerevisiae. FEBS Lett. 440: 325-331.

Francisci, S., Bohn, C., Frontali, L., and Bolotin-Fukuhara, M. 1998. Ts mutations in mitochondrial tRNA genes: Characterization and effects of two point mutations in the mitochondrial gene for tRNA $^{\text {Phe }}$ in Saccharomyces cerevisiae. Curr. Genet. 33: 110-116.

Giegé, R., Sissler, M., and Forentz, C. 1998. Universal rules and idiosyncratic features in tRNA identity. Nucleic Acids Res. 15: 5017-5035.

Helm, M., Brulè, H., Friede, D., Giegè, R., Putz, D., and Florentz, C. 2000. Search for characteristic structural features of mammalian mitochondrial tRNAs RNA 6: 1356-1379.

Li, S., Pelka, H., and Schulman, L.H. 1993. The anticodon and discriminator base are important for aminoacylation of E.coli tRNA $^{\text {Asn }}$. J. Biol. Chem. 268: 18335-18339.

Najarian, D., Shu, H.H., and Martin, N.C. 1986. Sequence and expression of four mutant aspartic acid tRNA genes from the mitochondria of Saccharomyces cerevisiae. Nucleic Acids Res. 14: 9561-9578.

Nissen, P., Kjeldgaard, M., Thirup, S., Polekhina, G., Reshetnikova, L., Clark, B.F., and Nyborg, J. 1995. Crystal structure of the ternary complex of Phe-tRNAPhe, EF-Tu, and a GTP analog. Science 270: 1464-1472.

Putz, J., Puglisi, J.D., Florentz, C., and Giegé, R. 1991. Identity elements for specific aminoacylation of yeast tRNA(Asp) by cognate aspartyl-tRNAsynthetase. Science 21: 1696-1699.

- 1993. Additive, cooperative effects between identity nucleotides of a tRNA. EMBO J. 12: 2949-2957.

Rinaldi, T., Francisci, S., Frontali, L., Zennaro, E., and BolotinFukuhara, M. 1994. Suppression of a mitochondrial point mutation in a tRNA gene can cast light on the mechanism of $3^{\prime}$ end processing. Curr. Genet. 25: 451-455.

Rohou, H., Francisci, S., Rinaldi, T., Frontali, L., and BolotinFukuhara, M. 2001. Reintroduction of a characterized mt tRNA glycine mutation into yeast mitochondria provides a new tool for the study of human neurodegenerative diseases. Yeast 18: 219-227.

Rould, M.A., Perona, J.J., and Steitz, T.A. 1991. Structural basis of anticodon loop recognition by glutaminyl-tRNA synthetase. Nature 352: 213-218. 
Saambrook, J., Fritsch, E.F., and Maniatis, T. 1989. Molecular cloning: A laboratory manual. Cold Spring Harbor Laboratory Press, Cold Spring Harbor, NY.

Sprinzl, M., Horn, C., Brown, M., Ioudovitch, A., and Steinberg, S. 1998. Compilation of tRNA sequences and sequences of tRNA genes. Nucleic Acids Res. 26: 148-153.

Varshney, U., Lee, C.P., and RajBhandary, U.L. 1991. Direct analysis of amino-acylation levels of tRNAs in vivo. J. Biol. Chem. 266: 24712-24718.
Westhof, E., Dumas, P., and Moras, D. 1988. Restrained refinement of two crystalline forms of yeast aspartic acid and phenylalanine transfer RNA crystals. Acta Crystallogr. A. 44: 112-123.

Wittenhagen, L.M. and Kelley, S.O. 2003. Impact of disease-related mitochondrial mutations of tRNA structure and function. Trends Biochem. Sci. 28: 605-611.

Zennaro, E., Francisci, S., Ragnini, A., Frontali, L., and Bolotin-Fukuhara, M. 1989. A point mutation in a mitochondrial tRNA gene abolishes its 3 '-end processing. Nucleic Acids Res. 17: 5751-5764. 

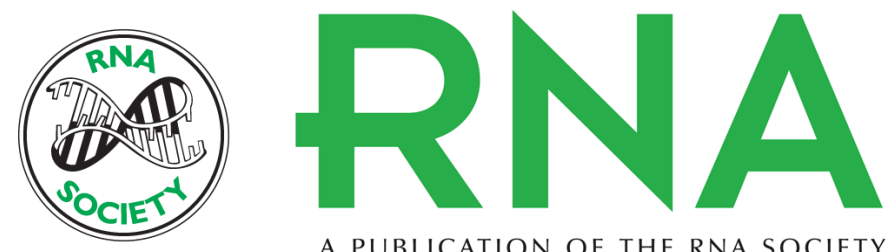

A PUBLICATION OF THE RNA SOCIETY

\section{Aminoacylation and conformational properties of yeast mitochondrial tRNA mutants with respiratory deficiency}

SILVIA FRANCISCI, CRISTINA DE LUCA, ROMINA OLIVA, et al.

RNA 2005 11: 914-927

References This article cites 22 articles, 5 of which can be accessed free at:

http://rnajournal.cshlp.org/content/11/6/914.full.html\#ref-list-1

License

Email Alerting Receive free email alerts when new articles cite this article - sign up in the box at the Service top right corner of the article or click here. 